\title{
The Use of Problem-Solving Heuristics Approach in Enhancing STEM Students Development of Mathematical Thinking
}

\author{
Parmjit Singh ${ }^{1 *}$, Sian Hoon Teoh ${ }^{1}$, Tau Han Cheong ${ }^{1}$, Nor Syazwani Md Rasid ${ }^{1}$, \\ Liew Kee Kor ${ }^{2}$, Nurul Akmal Md Nasir ${ }^{1}$ \\ ${ }^{1}$ Universiti Teknologi MARA, Selangor, MALAYSIA \\ 2 Universiti Teknologi MARA, Kedah, MALAYSIA \\ *CORRESPONDENCE: $\triangle$ parmj378@salam.uitm.edu.my
}

\begin{abstract}
One of the major aims of STEM education is the development of mathematical thinking. The common misconception is that "doing mathematics" is the same as getting involved in "mathematical thinking". Rallying to such argument, many would agree that mathematics should be taught as a thinking activity. Thus, this study endeavours to review the effects of a problemsolving heuristic application technique on learners' mathematical thinking development. This twophase study analysed the data utilising a descriptive design $(\mathrm{N}=660)$ and experimental design $(\mathrm{N}=54)$. In the first phase, 660 High School Leavers, with 93\% obtaining an A grade in the Math National Examination, ages $18-19$, registered with a college to undergo a two-year Diploma engineering program were administered a Mathematical Thinking Test. Then, fifty-four of these students participated in a seven-week Pre-Post experimental design to investigate the impact of heuristics application on their development of mathematical thinking. These student's post-test score was also compared with a batch of one hundred and twenty third-year university students $(\mathrm{N}=120)$ majoring in STEM related courses where all these students have taken at least five university level related math courses. Firstly, the results indicate that the high school leavers grades obtained in the national Examination was not translated into their Mathematical Thinking prowess. Secondly, the results depicted a significant increase in the mathematical Thinking posttest score among the students who underwent a seven-week pre-post problem solving heuristic treatment. Thirdly, the students involved in the heuristic application treatment performed better than the third-year students in the Mathematical Thinking test. It is vital that the heuristic method of teaching mathematics be employed to enhance student's development of mathematical thinking, especially for STEM students.
\end{abstract}

Keywords: heuristics, learning, mathematical thinking, STEM, mathematics, teaching

\section{INTRODUCTION}

The Science, Technology, Engineering and Mathematics (STEM) workers are of significant importance in maintaining the overall progress of the Malaysian economy and are an important factor in helping the nation towards being a developed nation. STEM education produces a generation of people who are creative thinkers, innovators and promotes science literacy (Eberle, 2010). This in turn culminates in new systems and products that support a nation's economy. This innovation and science literacy is an offspring of a deep foundation in the STEM areas. Without this base, students will not meet the criteria for various science related employments in the workplace. These include various job opportunities other than engineering and science. Malaysia as a

\footnotetext{
Article History: Received 19 August $2018 \bullet$ Revised 17 September $2018 \bullet$ Accepted 22 September 2018

(C) 2018 The Author(s). Open Access terms of the Creative Commons Attribution 4.0 International License (http://creativecommons.org/licenses/by/4.0/) apply. The license permits unrestricted use, distribution, and reproduction in any medium, on the condition that users give exact credit to the original author(s) and the source, provide a link to the Creative Commons license, and indicate if they made any changes.
} 
developing nation is facing a crisis in STEM education where fewer students are opting for the science field and the expected ratio of 60:40 for the enrolment of STEM and non-STEM programs at the tertiary levels is not being met. Various quarters have shown their concerns that more effort is needed to boost tertiary level students interest in the sciences as the situation, if allowed to continue, would lead to the country not being viewed in the same light as advanced nations (Nasa \& Anwar, 2016). It is an accepted fact that most jobs of the future will require science. The question to ponder upon is: Why are students losing interest in learning Science? Are teachers using the right approach? Is it our education system?

One of the primary components that cut across these disciplines in STEM education is mathematics as a core subject. The links between the fields of Science, Technology, Engineering and Mathematics is portrayed through the interdisciplinary Mathematical field, the education-based STEM, as reported by researchers (e.g. Chew, 2014; Nasarudin, Lilia, \& Effandi, 2014). The importance of mathematics is inevitable especially in STEM education where various physical phenomenon such as the conception of gravity, force, molecular kinematics, 3-D Digital Modelling correlates with mathematical models. The necessity of mathematics cannot be disputed because it provides a logical and systematic approach to the scientific process. Mathematics enables one to understand and analyse the link between quantities that are observed and measured.

It is widely accepted that mathematics is paramount in overcoming academic obstacles in the supply of science graduates in the field of engineering (Croft \& Grove, 2006; King, 2008). It is a pre-requisite of engineering courses to have a certain level of analytical proficiency in mathematics. Research has shown that students in science related fields faced great difficulty in their mathematics related courses (James \& High, 2008) and "it is now generally accepted that students entering the tertiary level suffer a lack of mathematical skills and no longer find mathematics to be an enjoyable subject ... this decline in mathematical skills leads students to avoid overly analytical subjects in later years of degree programmes" (Irish Academy of Engineering, 2004, p. 7). There is a belief among practitioners that there is a mutually exclusive context of math learning where mathematics learnt at tertiary level by students is not transferable into their employment contexts (Cardella, 2007; Pearson, 1991; Underwood, 1997). This was echoed by researchers in the engineering field (Bissell \& Dillon, 2000; Prieto, Bourke, O'Connor, Page \& Kira, 2009) they elucidated a vast disparity as to the views of a mathematician and an engineer as to what constitutes "doing mathematics". This phenomenon is prevalent all round the world and the most common measure taken is by doing more math as perpetuated by the saying 'practice makes perfect'. However, the common misconception is that mathematical thinking is equal to "doing mathematics". Rallying to such argument, many agree that mathematics should be taught as a thinking activity. This view has been echoed over the decade, that with the advent of technological progress, exchange of ideas through communication and the ease of obtaining information teaching "engineers to think analytically will be more important than helping them memorise algebra theorems" (Katehi, 2005, p. 152). There is no doubt that mathematics as a core subject is a fundamental pre-requisite for various STEM related courses especially among engineering practice. The question to ponder upon is "what is the nature of university/college students learning of mathematics especially in Malaysian contexts?" Have there been any assessments or ranking of tertiary students learning of mathematics? There is this tendency that no changes will occur until perturbation takes place. For example, communication skills in English Language among university graduates is a critical issue of concern at the current time related to employment and various measures are being taken by policy makers to curb these concerns. What about the role of mathematics at the tertiary level?

Malaysian students, aged 14 to 15 years old, participation in the international studies of Trends in Mathematics and Science Studies (TIMSS 2003, 2007, 2011 and 2015) and PISA have revealed dismal performance in mathematics over the last decade. An array of research, as well as mass media findings during these periods talk of the decline in Mathematical standards in the context of Malaysian schools over the years. The constant challenge students face when it comes to matters of problem solving in mathematics, especially so when interpretation and synthesis is involved denotes this low level of mathematical thinking. Absolute accuracy and precision could only ever exist in a utopian world. Hence, the arguments on TIMSS and PISA's rankings bearing no 'accuracy', though it could be argued, it would not hold much ground. It cannot, however, be doubted that at the very least, these studies serve as indicators, depicting the quality of the mathematics education system we have. Based on the ripple effect of TIMSS and PISA study, measures have been and is being taken to enhance students' aged 14 to 15 years on their cognition process in mathematics teaching and learning. For example, the Ministry of Education has placed high emphasis on Higher Order Thinking Skills (HOTS) and there is much support for classroom teachers in the form of professional development programs to introduce HOTS into their classroom teaching and learning, the introduction of HOTS questions into the 
main National and school examinations, and especially with the introduction of Malaysian Education Blue Print (2013-2025) program for school. What about students aged 18 to 19 entering the tertiary level? Are they prepared for the high cognitive demands of tertiary level education?

Much of the issues on the low decry of tertiary level student's mathematics performance have been barged on the foundation laid by school mathematics. Studies in both local (Aida, 2015; Intan, 2016; Parmjit, Teoh, Nor Syazwani, Nurul Akmal,Cheong, Norziah, 2016) and international contexts (Adams, 2014; Atuahene \& Russell, 2016; Borsuk, 2016; Camera, 2016; Conley, 2003; English \& Kirshner, 2015) have collectively agreed that majority of the students, upon the completion of high school, are still not equipped with the necessary skills and development that could meet the demands and expectations with regards to intellect necessity in college. A lot of debates have taken place in blaming schools for this problem but researchers at the tertiary level need to ask what can be done to resolve the issue. One solution is to teach mathematics as a thinking activity (Devlin, 2013; Liu, \& Niess, 2006). This activity provides students with "problem solving tools" that would allow them to be accommodative to changing needs (Treffinger, Selby, \& Isaksen, 2008). These tools can be employed if there is a higher level of thinking which can be inculcated through progressive awareness (Nasarudin, et. al., 2014). The use of such "tools" with non-routine problems is the capstone towards students' development of mathematical thinking.

\section{Non routine Problems}

One cannot deny the importance of problem solving in the study of mathematics. One of the vital roles of mathematics teaching and learning is to inculcate the ability to solve different and abstract mathematical problems. Problem solving can be categorized into two types namely routine and non-routine problems. Routine problems as sometimes referred to as "practice make perfect" or "plug-and-chug" problems (Duch, 2001) or "symbolic knowledge" (Kieran, 1988) or "skill and drill" problems place emphasis on the procedures rather than the process of learning and it do not contribute to the development student's cognitive growth (Polya, 1962). This is because when students attempt these problems, their focus is on the product rather than the process. To put it simply they do not take into consideration context, structure and situations, and students lose the opportunity to give rise to the "richly inter-connected spaces" that Cooper (1988) has recognized as a vital part of constructing mathematical knowledge. Thus, the byproduct are islands of superficial knowledge without a canoe to get from one end to the other. On the other hand, Polya suggested that in order to develop students higher order thinking growth, non-routine problems should be adopted.

Non-routine problems are problems that do not have a direct solution to a given task. In other words, a task is non-routine if the procedure or method of solution is not immediately known, and hence requires an action to apply creativity and previous constructed knowledge in new and unfamiliar situation. In this problem, procedural orientation will not guarantee a solution. As Polya (1973) puts it:

To have a problem means to search consciously for some action appropriate to attain some clearly conceived but not immediately attainable aim. To solve a problem means to find such an action (p. 99).

The actions as surmised by Polya include by "drawing on the pertinent subject knowledge and objectively and critically assessing the quality, accuracy and pertinence of that knowledge rather than trying to combine various memorized ample solutions". It involves an exploratory phase and an "understanding" develops throughout the problem solving process (Woods, et al, 1997).

An example from the study by Parmjit and Teoh (2016) is illustrated below to elucidate the difference between routine and non-routine problem. This task was administered among High school leavers.

Task:

a) Find the area of the right-angle triangle in Figure 1 (routine problem).

b) Find the area of the right angle isosceles triangle in Figure 2 without the aid of Pythagoras or trigonometry functions (non-routine problem). 
Figure 1. Routine problem 1

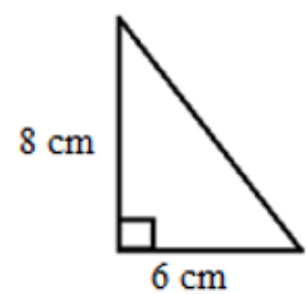

Figure 1. Routine problem 1

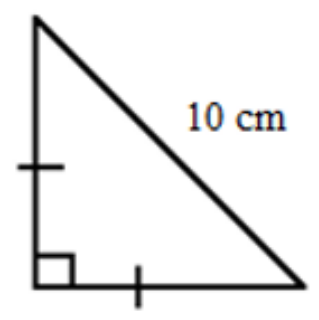

Figure 2. Non-routine problem 1

Solution

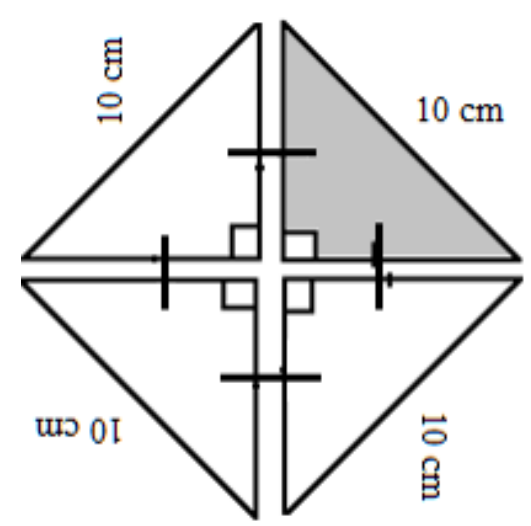

Figure 3. Solution of non-routine problem 1

When the shaded region is constructed geometrically, it will formed a quarter of a square yielding an area of $25 \mathrm{~cm}^{2}\left(1 / 4 \times 100 \mathrm{~cm}^{2}\right)$.

Their finding reveals only $15 \%$ of the high school students (as compared to $100 \%$ success rate for item in Figure 1) were able to solve the problem without the aid of Pythagoras or trigonometry functions. Regardless of the fact that mathematical learning has been ongoing for a significantly long duration (from primary, secondary to university), many research studies have shown that learners dearth of key cognitive strategies and lack confidence, as well aptitude in approaching non-routine mathematical related problems (Asman \& Markowitz, 2001).

Simulating classroom practices with non-routine mathematics tasks is indeed important to equip learners with the heuristics required to teach non-routine problem solving in their future mathematics classroom. Nonroutine problems refer to problems that are within the zone of proximal development and yet challenging. Another example for illustration. What is $0 / 0$ ? We all know for a fact (or nearly all) that's it is undefined. Yet, an algorithmic procedure can be illustrated to show its contrary. 


$$
\begin{aligned}
\frac{0}{0} & =\frac{10^{2}-10^{2}}{100-100} \\
& =\frac{(10+10)(10-10)}{10(10-10)} \\
& =\frac{20}{10} \\
& =2
\end{aligned}
$$

Is this true? If Yes, why and if No, why? Please explain. This problem stimulate students to think because they know the answer is undefined and yet, seem mathematically correct!

Another example:

There were a number of students in the classroom and a total of 36 handshakes took place among the students. Each student shook hands once and only once with everyone else. How many students were in the classroom? Using an algorithmic procedure is usually futile if one is not able to comprehend the problem. Thus, one requires some heuristic approach in attempting to solve the problem.

\section{What are Heuristics}

Heuristic, as an adjective, means "serving to discover" (Polya, 1973. p.112-113). This approach is based on the principle of learning by doing. H. E. Armstrong (1888-1928, cited in Maheswari, 2016) first propounded such a method of teaching, which he described as placing students in the ocean of discovery, as deep as possible. According to him, "Heuristic methods of teaching are methods where students are placed into the mode of a discoverer opposed to the traditional mode of receiver of information or simply being told about things (p.144). He further elucidated the very fibre of the heuristic method is to place the student as an investigator who finds meaning and not a recipient of information that is "told". Decades later, Polya popularise its usage where he elucidated, heuristics are methods employed for succeeding in uncommon or non-routine problems. In other words, heuristic strategies are seen as the modus operandi for successful problem solving, or at the least offer some general suggestion(s) that assist one in better understanding of a problem or solve it successfully. It is the knowledge of problem solving techniques, methods and procedures with the aim "to study the methods and rules of discovery and invention" (p. 112).Expressions such as to "simplify an algebraic expression by removing parentheses," to "make a table," to "restate the problem in your own words," or to "draw a figure to suggest the line of argument for a proof" are heuristic in nature. These heuristics are the benchmark set in attaining success in tackling difficult problems (Polya, 1973). They are the basics of the technique that we can formulate in solving problems (Schoenfeld, 1988).

Example:

It was Aisyah's first day at school. The class teacher introduces Aishah to all the 8 students in the class. Aishah shakes hands once and only once with all 8 students in the class. How many total handshakes were there?

Solution

Heuristic: Making a Table

\begin{tabular}{lllllllll}
\hline No of students & 1 & 2 & 3 & 4 & 5 & 6 & 7 & 8 \\
\hline No of handshakes & 0 & 1 & 3 & 6 & 10 & 15 & 21 & $?$ \\
\hline & & $\mathbf{+ 1}$ & $\mathbf{+ 2}$ & $\mathbf{+ 3}$ & $\mathbf{+ 4}$ & $\mathbf{+ 5}$ & $\mathbf{+ 6}$ & \\
\hline
\end{tabular}

From the table following a pattern,

For 2 students, there will be one handshake

For 3 students, there will be three handshakes $(1+2)$.

For 4 students, there will be six $(1+2+3)$ handshake

Following the pattern, for 8 students the number of handshakes will be $21+7=28$ handshakes or $(1+2+3+4+5+6+7)$.

Several studies have employed heuristic processes. Kantowski (1977) helped his secondary school students solve geometry problem solving questions using heuristic instruction. Wilson (1967) and Smith (1974) studied 
the variation between general and task specific heuristics. These studies found a positive impact on the usage of heuristics as a tool in solving problems. It is important to reiterate that heuristic strategies are not a replacement for subject knowledge but rather serve as a guide for uncommon types of problems. Frequently, the usage of heuristic strategy is heavily dependent on a firm foundation of domain-specific resources. Thus, for this study, the samples have learnt the subject matter knowledge through their formal learning in schools that enabled us to assess the quality of this learnt knowledge in relation to their application in solving nonroutine problems. The heuristics that students were exposed in this study among others include drawing diagram, looking for pattern, making a list, working backwards and guess \& check. In this study, we investigate the effect of the use of problem-solving heuristics approach in enhancing student's development of mathematical thinking. We utilised heuristic as an approach to enhance student's development of mathematical thinking.

Mathematical thinking is considered a vital ingredient in the workplace. According to Breen and O'Shea (2010, p. 42), mathematical thinking involves "conjecturing, reasoning and proving, abstraction, generalisation and specialisation". Schoenfeld (1992) is of the view that it is no longer valid to have a syllabus where one simply masters mathematical facts and procedures and does not promote mathematical thinking. According to him, "learning to think mathematically" means (a) having a stand point in mathematics by applying mathematics knowledge, and (b) developing the ability to use the tools of the trade, and applying these to understanding or sense making by using mathematics. Mathematical thinking in this study utilised the definition as propounded by Devlin (2012), where he elucidated it as a way of learning a math concept by dissecting and analysing it till its numerical and structural roots and reasoning patterns. In developing students thinking, the problem posed must be challenging, stimulating and within their zone of proximal development.

In this heuristic approach in developing cognitive thinking towards the development of mathematical thinking, problem solving as a tool was used to elicit the thinking process where students participated in a variety of exercises, problems, and investigations as they explored mathematics concepts from a problemsolving perspective in an interactive manner through various heuristics. The emphasis was on exploration of various mathematics contexts to learn mathematics, to solve problems, problem extensions, and to communicate mathematical demonstrations. Thus, the prime aim of the study was to investigate the impact of heuristics approaches on students' development of mathematical thinking with the objectives:

a) to determine the current level of High School leavers and 3rd Year University Students (Majoring in Mathematics, Science and Engineering) attainment in the Mathematical Thinking Test

b) to investigate the effect of heuristic teaching method on High School leavers achievement in the Mathematical Thinking test and its comparison with 3rd Year University Students.

\section{METHODOLOGY}

This two-phase study utilised a purely quantitative approach involving a descriptive design and an experimental design. Descriptive design seeks to investigate the current condition of an identified variable. The descriptive design was undertaken to depict a picture of student's capability in solving non-routine problems. On the other hand, a quasi-experimental design was used with the aim to establish cause effects relationships among the variable, namely heuristics as the treatment (independent variable) and the mathematical thinking test (dependent variable). In other words, this experimental design enabled the researchers to assess the effectiveness of the heuristics as a tool in enhancing student's development of mathematical thinking.

In the first phase, a Mathematical Thinking Test was administered to 660 High School Leavers, ages 19 to 21 , registered for a diploma program in an engineering program at a local university. The first three months of the program comprised preparatory courses which included, among others mathematics, physics, and general studies. After undergoing the preparatory course, the students were divided by the university administrators into three different programs namely civil, electrical and mechanical comprising 16 intact classes within them.

For comparison purposes, this test was also administered to 120 final year college students' ages, 23 -24, majoring in mathematics, science and engineering towards obtaining their Bachelor of Science degree. These students were selected based on stratified sampling in relation to the proportions in the three programs. The rationale for choosing these samples were, that they, have formally taken the standard university 
mathematics required courses (over the semesters) namely, Calculus 1, Calculus 2, Mathematical Logic, Numerical Analysis, Differential equations and this gave the researchers the opportunity to assess their ability to "utilize" their knowledge. In other words, it is to investigate if these degree students could (after taking the various math courses over the semesters) apply their knowledge in solving fundamental problems which required them to think.

In the second phase, fifty-four students from two intact classes were randomly selected based on blocked sampling from the sixteen classes, to participate in a One Group Pre-Post Quasi Experimental Design with the aim to explore the effects of a problem-solving heuristic instructional approach on learners' mathematical thinking development. In the education settings, random assignment of students into different group was difficult due to the institution rules and policy as it would disrupt the original classroom learning experiences. Thus, for that reason, intact block sampling method is appropriate in such educational setting to represent the population of study (Creswell, 2008). These selected 54 samples (mean=9.91, SD=5.82) could be viewed as a representative of the total population of the 660 samples (mean=9.55, $\mathrm{SD}=5.50$ ) based on the similarity mean scores obtained between the two groups.

To determine if the selected groups were normally distributed, the Shapiro-Wilk test was conducted. The analyses of the $\mathrm{p}$ value indicate $\mathrm{P}>0.05$ depicting both sets of data groups were normally distributed. Thus, this design attempts to establish a cause effects relationship with the variables of study namely mathematics thinking scores. This group was engaged with the intervention for a total of 7 weeks with 2 hours for each week.

A mathematical thinking instrument comprising 10 items was adapted from Parmjit et al. (2016). The problems in the test did not require the usage of a calculator or any formulae that needed to be memorized. In other words, it is the ability to think, try out, and prove which demonstrates the students' mathematical knowledge by testing and refining previously learnt conjectures.

Examples of the problems include:

- Three water hoses are used to fill a children's swimming pool. The first hose alone takes 3 hours to fill the pool, the second hose alone takes 4 hours to fill the pool, and the third hose alone takes 12 hours to fill the pool. If all three hoses are opened at the same time, how long will it take to fill the pool? Please explain.

- Eva and Alex want to paint the door of their garage. They first mix 2 cans of white paint and 3 cans of black paint to get a particular shade of gray. They add one more can of each. Will the new shade of gray be lighter, darker or are they the same?

- Eighteen people, numbered 1 to 18 , are equally spaced around a round table. What is the number of the person directly across from the person numbered 6 ?

- There were a number of students in the classroom and a total of 36 handshakes took place among the students. Each student shook hands once and only once with everyone else. How many students were in the classroom?

For a period of seven sessions of 2 hours each, the experimental group was subjected to the problem solving heuristic approach. These students were explicitly taught heuristics as a mathematical concept. The potential heuristics possible to solve a given task and each heuristic was explicitly explained during the problem-solving process. This methodology was taken in relation to Tiong's et al. (2005) rationale that if only each specific heuristic is taught at a time in solving a task, the various heuristics available are isolated from one another and this might sway students to treat heuristics as algorithms procedures to be followed.

Steps in heuristics teaching methodology

- First, students were assigned a few non-routine problems, problems that perturbed one's thinking or that cannot be solved immediately.

- Students were given adequate time to think on their own to construct their own representation [possible representation include e.g. enactive (physical), iconic (visual), and (symbolic)]. This enables them to cognize their representation.

- Students were asked to come up with a presentation before the class, on their representations and offer an explanation as to why they represented the problems the way they did. Other students were encouraged to comment on these representations. 
Table 1. High School Leavers (SPM Mathematics) results by gender

\begin{tabular}{|c|c|c|c|c|c|}
\hline & & $\overline{\mathrm{A}}$ & 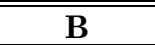 & 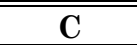 & Total \\
\hline \multirow{2}{*}{ Gender } & Male & 395 & 26 & 3 & 424 \\
\hline & Female & 220 & 15 & 1 & 236 \\
\hline \multicolumn{2}{|c|}{ Total } & $615(93.0 \%)$ & $41(6.2 \%)$ & $4(0.8 \%)$ & 660 \\
\hline
\end{tabular}

Table 2. Third Year University Students by Gender

\begin{tabular}{cccc}
\hline & & Frequency & Percent \\
\hline \multirow{3}{*}{ Gender } & Male & 36 & 30.0 \\
\cline { 2 - 4 } & Female & 84 & 70.0 \\
\cline { 2 - 4 } & Total & 120 & 100.0 \\
\hline
\end{tabular}

- Students were then given sufficient time to solve the problems with the representations they created.

- Again, students were asked to present their work, they were given more time to solve the problems, present them and discuss the solutions.

- Introduce the concept of "bringing in solutions" as problem solving modes, and ask them to comment on such methods, and why and when they think it will be useful.

- We then ask them to solve the problems using as many ways as they could, utilizing any approach, and then offer an explanation of their preferred approach.

\section{RESULTS OF STUDY}

\section{Background information of student's participation in the study}

Table 1 shows a total of 660 high school leavers who participated in this study comprising $64.3 \%(n=424)$ males and $35.7 \%(n=236)$ females. From this data, $93.0 \%(n=615)$ of the students obtained an A grade in their National Examination Math Results (SPM) followed by $6.2 \%(n=41)$ and $0.8 \%(n=5)$ with B and C grades respectively. Based on the National Examination mathematics result as shown in Table 1, we can surmise that the students involved in the study have an above average ability in their mathematics achievement.

Table 2 shows one hundred and twenty third-year university students majoring in the field of science (Mathematics, Physics and Engineering) who participated in the study with the gender composition of $30 \%$ $(n=36)$ and $70 \%(n=84)$ of males and females respectively.

Based on the demography description above, the 660 high school leavers that excelled in mathematics 93\% ( $n=615)$ of them obtained an A in the Mathematics examination at the SPM level. On the other hand, one can also consider all the 120 university students (majoring in Mathematics, Physics and Engineering) to excel in mathematics because they are Third year students who have taken various university level mathematics related courses.

\section{This section details the findings of study based on this two-phase study.}

In phase 1, a descriptive analysis was provided in comparing the scores obtained in the Mathematical Thinking Test by both School Leavers and Third Year University Students. It is significant to highlight that the selection of the Third-Year university students was for the purpose of comparisons only.

Research Question 1: What is the level of students'attainment in the Mathematical Thinking Test among i) High School Leavers? ii) Third Year University Students?

Table 3 provides the descriptive analyses scores of the Mathematical Thinking Test where both the High School Leavers and Third Year Students participated. The means score obtained by the high school leavers and university students were $9.55(\mathrm{SD}=5.50)$ and $10.50(\mathrm{SD}=5.72)$ out of a maximum score of 40. In other words, the percentage score for each of these groups were $23.9 \%(9.55 / 40 \times 100)$ and $26.3 \%(10.5 / 40 \times 100)$ respectively. These findings indicate both high school leavers and university students attained a low-level score in the mathematical thinking test. 
Table 3. Students' Score in the Mathematical Thinking Test

\begin{tabular}{lcccc}
\hline & N & Mean & S.D & Percentage \\
\hline High School Leavers & 660 & 9.55 & 5.50 & 23.9 \\
\hline 3rd Year University Students & 120 & 10.50 & 5.72 & 26.3 \\
\hline
\end{tabular}

Max score: 40

Table 4. Paired sample t-test between pre-test scores and post-test scores among High School Leavers

\begin{tabular}{ccccccc}
\hline & Mean & N & SD & t & df & Sig (2-tailed) \\
\hline Pre-Test & 9.91 & 54 & 5.82 & -6.334 & 53 & .000 \\
\hline Post-Test & 15.67 & 54 & 7.00 & & & \\
\hline
\end{tabular}

Max Score: 40

Table 5. Descriptive Statistics of School Leavers Post-Test with Final Year Students Score in the Mathematical Thinking Test

\begin{tabular}{lcccc}
\hline & N & Mean & S.D & Percentage \\
\hline High School Leavers Post-Test & 54 & 15.67 & 7.00 & 5.72 \\
\hline 3rd Year University Students & 120 & 10.50 & 39.2 & 26.3 \\
\hline
\end{tabular}

In comparison of the scores obtained between high school levers (Pre-Test) and university students of 9.55 $(\mathrm{SD}=5.50)$ and $10.50(\mathrm{SD}=5.72)$ respectively. It can be concluded that there is a minimal difference of 0.95 . It somewhat indicates that there is not much difference in the mean score obtain by high school leavers who generally excel in mathematics (Based on their SPM Math Grades) and university students who have taken various university level math courses.

In the second phase, a One Group Pre-Post Quasi Experimental Design was utilized among fifty-four high school leavers, with the aim of exploring the effects of a problem-solving heuristic instructional method on learners' mathematical thinking development. It attempts to establish cause effects relationships with the variable of study namely mathematics thinking scores. It is acknowledged that this one-sample experimental design has its limitations because there is no baseline measurement against groups that remained untreated. It was unavoidable as it is of ethical issues of dividing college learning students into control groups (with no treatment) as compared to the experimental group during their teaching and learning process in college.

Research Question 2: Is there a significant difference in mean scores of the Mathematical Thinking Test between pre-test and post-test among the High School Leavers?

The hypothesis to be tested is:

There is a significantly higher mean score in the post test than in the pre-test.

Table 4 shows that the mean score between pre-test and post-test scores obtained by the high school leavers involved in the problem-solving heuristic instruction approach is $9.91(\mathrm{SD}=5.82)$ and $15.67(\mathrm{SD}=$ 7.00) respectively. To investigate if the heuristic instruction approach has any significant effect on High School leavers achievement in the Mathematical Thinking test, a paired sample t-test analyses was conducted. The result (refer Table 4) shows that there is a significant difference in mean scores $[\mathrm{t}(53)=-6.334, \mathrm{p}<.05]$ between pre-test scores and post-test scores at the .05 level. The findings support the hypothesis that improved scores in Mathematical Thinking are achieved through participation in the 7 weeks' problem-solving heuristic instructional approach.

Table 5 shows the descriptive statistics of the Post-test scores between High school leavers who participated in the experimental design with the Third Year University students.

The descriptive statistics show that the post-test scores of high school leavers $(\mathrm{M}=15.67, \mathrm{SD}=7.00)$ is higher as compared to the Third-year university students (Mean=10.50, $\mathrm{SD}=4.72$ ) who have taken the various university level mathematics courses. There is a difference of $12.9 \%$ between these two groups of students. In other words, this signifies that High school leavers mathematical thinking development is significantly enhanced as compared to the various university level math courses taken by the students over the past five to six semesters. 


\section{DISCUSSION}

The aim of the study was to investigate the current level of high school leavers and university students (majoring in STEM education courses) attainment level in mathematical thinking and secondly to investigate the effect of heuristics approaches on students' development of mathematical thinking.

The findings of the study show both the High School leavers $(\mathrm{N}=660)$ and Third year university students $(\mathrm{N}=120)$ obtained a low score of $23.85 \%($ mean $=9.54$, max score $=40)$ and $26.3 \%($ mean=10.50, $\max$ score $=40)$ respectively in the Mathematical Thinking test. This indicates that Math grades obtained by high school students (despite of $93 \%$ of them obtaining an A grade in the national examination) and university students who has taken various university level mathematics courses (such as Calculus 1, Calculus 2, Algebra, Engineering Mathematics etc.) for the respective programs does not translate into their mathematical thinking development. This finding of High school leavers low attainment correlates with previous findings (Atuahene \& Russell, 2016; Borsuk, 2016; Boaler \& Zoido; 2016; Camera, 2016; English \& Kirshner, 2015, Hughes, et. al., 2015; Intan, 2016; Parmjit, et. al.,2016) that these students lacks the intellectual capacity needed for early years at college. Boaler and Zoido (2016) studies show that over reliance on memorization, rote procedures has a negative impact on meaningful learning and high school grades do not reflect that a student is prepared for college-level work (Atuahene \& Russell, 2016). On the other hand, English and Kirshner (2015) argued the importance of inculcating non-routine problems in enhancing students intellectual capacity of mathematical thinking that will enable them to be "mathematically flexible" whilst developing basic concepts and ideas of mathematics and working on the problem-solving process. The mere learning of mathematics through practices and procedures will limit their mathematical intellectual capacity (Hughes et al., 2015).

Similarly, the finding from the undergraduates also somewhat correlated with previous research that opines that in present times, college mathematics are premised almost solely on formal mathematical algorithm, concepts, and procedures that appear highly far-fetched from the conceptual understanding amongst students who seek to learn them (Bowyer \& Darlington, 2016; Hanford, 2012; Parmjit, 2009; Parmjit \& White, 2006; Saritas \& Akdemir, 2009). For example, Bowyer and Darlington (2016) expressed concerns regarding current undergraduates' majoring in STEM courses mathematical capabilities in the context of lacking mathematical fluency, analytical ability and an appreciation of the importance of proof. Among the concerns voiced were:

- Students are less prepared to think and apply mathematics in different contexts than in the past: they are "more brittle", not less bright. Lecturers want students to demonstrate a mathematical argument but students seem to seek templates (p.17)

- The main problems are students' mathematical fluency, rather than specific content or topics. Students struggle with selecting and applying the mathematics they already know, even in situations they should be familiar with (such as differentiating and integrating) (p.20)

Their finding depicts that over the years, skills with regards to computation formed the crux of competency tests, with the generation of tutorial sheets and instructional emphasis as means to form such development. Students involved in this study lack the ability of thinking and solving problems although they seem to have "mastered" numerical computations. Hanford (2012) stated that findings from various studies over the decades revealed that to expect college students to conceptualize math learning from classroom teaching alone, is an expectation unrealistic in its form. However, the stark reality of current times seemed to denote that this is essentially the way in which mathematical teaching is carried out in college. There is evidence that university students also face the challenge of reasoning and applying mathematical concepts just as the high school leavers do. It seems that there has been no shift in conceptual understanding of mathematics after formal instruction. It is evident that with the advent of companies that rely on data for decision making, it is of paramount importance to employ people who have the ability to analyze and interpret data in meaningful ways in arriving at decisions. Employees who do not deal directly with data are expected to, at least, have an understanding of the basics of what the data conveys.

The prime objective of this study in investigating the effects of heuristics approach in enhancing the development of mathematical thinking showed a significant increase in the mathematical Thinking Pre-TestPost-Test score among the students who underwent the seven-week problem solving heuristic treatment. Using the quasi experimental design, the heuristic instruction approach enhanced students' development from a mean score of 9.91 to15.67, from a maximum score of 40 . In other words, there was an increment of 5.76 or 
$58.1 \%$ between the pre-test and post-test scores. As postulated by Polya (1973), heuristics acts as reasoning tools and methods of discovery and invention. In this study, students were explicitly taught heuristics as a mathematical concept where they were exposed on the various heuristics possible to solve a given task. This usage and flexible application of heuristics does seem to aid students to direct their thinking towards solving the given non-routine problems. This finding corroborates with the wide spread agreement that the heuristic approach to problem solving allows the enhancement of conceptual mathematical understanding within learners (English \& Sriraman, 2010; Schroeder \& Lester, 1989). Problem solving is a multi-faceted tool that gives rise to a well gripped understanding that provides a link between the problem and the number of facts (Carpenter et al., 1989; Kilpatrick et al.; Swafford \& Findell, 2001). The problems posed to students in this study were within their zone of potential construction, seemed easy and yet challenging. In order for students to show interest, Cai (2003, p.247) puts forth that the problems posed to learners should be stimulating and engage their knowledge as well as to enhance this knowledge. This surmises that heuristics is a necessity to be formally taught among students with the same importance as any other mathematical concept (Schoenfeld, 1980). Furthermore, students should be given plenty of time and opportunities to reflect using the different strategies, since problem-solving ability develops slowly over a prolonged period of time (Randall \& Lester, 1984). It is important to note that, although the heuristic method could serve as guideline in the solution of relatively unknown problems, it cannot replace knowledge of subject content. Quite often the successful implementation of a heuristic strategy is based on the fixed foundations of subject specific knowledge (Schoenfeld, 1985). In other words, with the introduction of the domain of heuristics as a tool of learning together with the domain of math concepts (to be learnt), we strongly believe both these domains propagates a way of completing the learning of mathematics concepts rather than competing with each other.

Yet, it is significant to highlight that there have been virtually no reforms that are aimed at changing the pedagogy perspective especially the teaching and learning process of the particular content in colleges. Many schools have introduced curriculums on entrepreneurship, study skills, time management. There is a mushrooming of leadership and motivational courses to inspire learners in their pursuit of academic excellence (Zachry, 2008; Zeidenberg, Jenkins, \& Calcagno, 2007). For those who face financial constraints, schools have worked with various institutions that offer loans packages to ease student's financial burdens. They have created various technological platforms of technology usage such as Mobile-learning, e-learning, blendedlearning and now MOOC learning over the decades to enhance teaching and learning. There has been a revolution in curriculums from acceleration to slowing down to excluding certain topics that are deemed unnecessary (e.g., Lucas \& McCormick, 2007). However, only a minority have raised queries on the teaching methodology of mathematics (Zachry, 2008) especially in college settings.

\section{CONCLUSION}

The findings show that both high school leavers with $93 \%$ of them obtaining an A Grade in the national examination in Math and University students majoring in STEM field have a low level of mathematical thinking aptitude. There is a high probability that the methods used to teach mathematics in school does not differ much from those used in university (Grubb, 1999). Most instructions still employ the "drill-and-skill" method (Bowyer \& Darlington, 2016; Goldrick-Rab, 2007). Thus, students who failed to conceptualize dy/dy in high school and over focusing on algorithms are faced with the same challenge in university courses. Thus, it is not surprising that methods that did not work in high schools also don't work in university learning. There has been almost no progress thus far in the teaching of mathematics.

The correlation between classroom learning and real life is not very evident to college students. From the perspective of mathematics as a core subject in engineering education, Radzi, Abu, and Mohamad (2009) are of the view that mathematics should empower students to think critically and creatively and beyond their foundational knowledge of the subject. They further elucidate that one should be able to interpret information mathematically and utilize mathematical knowledge to address problems and arrive at solutions meaningfully. Forms of rote learning such as memorizing facts, algorithms, equations and more, as far as mathematics is concerned, robs a student off their critical thinking faculties as they do not engage in the construction of relationship between concepts and patterns. As Wheatley put it, they may lose the mathematical link in the problem (Wheatley, 1991). The consequential impact is negatively felt when such approach is no longer viable and usable in a higher level of tertiary education.

It is acknowledge that the findings from the experimental one group pre-post-test design used in this study does have some limitation based on the lack of random students assignment to the experimental group and the block sampling for students selection. Conducting a randomized controlled trial was neither logically 
possible or ethical in this study. Thus, this somewhat does compromise the validity of study. As such, the design in this study serves as an intermediary to determine grounds for subsequent, focused, true experimental designs in the same area of interest.

To sum up, every student learning mathematics is expected to gear up with knowledge of reasoning and thinking skills in making informed choices on complex matters. The effort of gearing up within their mathematical knowledge comes from many tries which in turn, is called habits of mind or thinking habits. However, inability in terms of meeting proficiency standards are a matter so complex, that to put the blame on the learners isn't altogether fair. If no measures are taken in curbing these issues, students will have a negative attitude towards the learning of mathematics especially in the current context of STEM education. The college students caught in the straddles of struggle would end up looking at mathematics in a negative light, and subsequently develop a negative attitude towards the subject matter. The problem lies in not regulating the matter in its infant stages. Students then resort to attending tuitions, extra classes and many more remedial programs which merely serve as extraneous to what the students already experience in college lectures. Most of these do not pour out a positive result. A saying goes that, if you keep doing the same thing, you will keep getting the same results and that is precisely what has been happening, as despite the low success rate of this remedial solutions, many still rely on them to attain some form of mathematical salvation. The low percentage of college students enrolling in STEM related fields reflects this.

This study shows that the application of heuristics has a positive effect on student's development of mathematical thinking. "The aim of heuristics is to study the methods and rules of discovery and invention" (Polya, 1973, p. 112). It helps learners to come up with different ways of solving problems through discovery. We are conjecturing that there is a dire need to introduce a Mathematical Thinking Heuristics Approach application as a course in enhancing student's cognitive growth in mathematics learning. The problem-solving heuristics approach used in the study was successful because the experiences created in the learning process exposes students to stimulating problem situations, propagates the generation of fundamental mathematical ideas and using the learnt heuristics in trying to solve the assigned problems. These problems also measure critical thinking, problem solving, and logic based on fundamental conceptions of mathematics and not just mere math skills. In other words, this mathematical thinking test used in the study is somewhat an aptitude test on cognitive assessment of mathematics. We are of the view that this heuristics application be considered as a course for both tertiary and school students in enhancing students' knowledge in general and STEM Students in particular, for the development of mathematical thinking. This heuristics application will not be competing with the mathematics courses currently being taught but rather, will be completing it as a holistic package towards students mathematical thinking development.

\section{ACKNOWLEDGEMENTS}

This work was supported by University Teknologi MARA, Malaysia Grant Scheme (Project Number: CoRe82/T5/2015(17)/HDC(6))

\section{Disclosure statement}

No potential conflict of interest was reported by the authors.

\section{Notes on contributors}

Parmjit Singh - Universiti Teknologi MARA, Selangor, Malaysia.

Sian Hoon Teoh - Universiti Teknologi MARA, Selangor, Malaysia.

Tau Han Cheong - Universiti Teknologi MARA, Selangor, Malaysia.

Nor Syazwani Md Rasid - Universiti Teknologi MARA, Kedah, Malaysia.

Liew Kee Kor - Universiti Teknologi MARA, Selangor, Malaysia.

Nurul Akmal Md Nasir - Universiti Teknologi MARA, Selangor, Malaysia. 


\section{REFERENCES}

Abdullah, N., Halim, L., \& Zakaria, E. (2014). VStops: A Thinking Strategy and Visual Representation Approach in Mathematical Word Problem Solving toward Enhancing STEM Literacy. EURASIA Journal of Mathematics, Science \& Technology Education, 10(3), 165-174. https://doi.org/10.12973/eurasia.2014.1073a

Adams, C. (2014). High School Graduates Feel Unprepared For College and Work, Survey Finds. Retrieved on July 11, 2018 from http://blogs.edweek.org/edweek/college_bound/2014/12/high_school_grads_ unprepared_for_future.html

Aida Suraya (2015). Developing students' mathematical thinking: How far have we come? Retrieved on July 12, 2018 from http://www.educ.upm.edu.my/dokumen/FKKDI1_BULETINEDUC.pdf.

Atuahene, F., \& Russell, T. A (2016). Mathematics Readiness of First-Year University Students. Journal of Developmental Education, 39(3), 12-32.

Bissell, C., \& Dillon, C. (2000). Telling Tales: Models, Stories and Meanings. For the Learning of Mathematics, 20(3), 3-11.

Boaler, J., \& Zoido, P. (2016). Why math education in the U.S. doesn't add up. Retrieved on Aug 27, 2018 from https:/www.scientifcamerican.com/article/why-math-education-in-the-u-s-doesn-t-add-up/

Borsuk, A. J. (2016). Too many students unprepared for college. Retrieved on July 12, 2018 from http://www.jsonline.com/story/news/education/2016/10/08/borsuk-too-many-studentsunpreparedcollege/91750628/

Bowyer, J., \& Darlington, E. (2016). Applications, applications, applications. Lecturers' perceptions of students' mathematical preparedness for STEMM and Social Science degrees. Retrieved on July 12, 2018 from http://www.cambridgeassessment.org.uk/Images/419688-lecturers-perceptions-of-studentsmathematical-preparedness-for-stemm-and-social-science-degrees.pdf

Breen, S., \& O'Shea, A. (2010). Mathematical Thinking and Task Design. Irish Math. Soc. Bulletin, 66, 39-49.

Cai, J. (2003). What research tells us about teaching mathematics through problem solving. In F. K. Lester (Ed.), Teaching mathematics through problem-solving: Prekindergarten - Grade 6 (pp. 241-253). Reston, VA: NCTM.

Camera, L. (2016). High School Seniors Aren't College-Ready. Retrieved on July 12, 2018 from http://www.usnews.com/news/

Cardella, M. (2007). What Your Engineering Students Might Be Learning From Their Mathematics Pre-Reqs (Beyond Integrals and Derivatives). 37th American 455 Society for Engineering Education (ASEE) / Institute of Electrical and Electronics Engineers (IEEE) Frontiers in Education Conference. City: Milwaukee, WI, pp. S4F1-S4F6.

Carpenter, T. P., Fennema, E., Peterson, P. L., Chiang, C. P., \& Loef, M. (1989). Using knowledge of children's mathematics thinking in classroom teaching: An experimental study. American Educational Research Journal, 26(4), 499-531. https://doi.org/10.3102/00028312026004499

Conley, D. T. (2003). Mixed messages: What state high school tests communicate about student readiness for college? Eugene, Ore.: Center for Educational Policy Research, University of Oregon.

Croft, T., \& Grove, M. (2006). Mathematics Support: Support for the Specialist Mathematician and the More Able Student. MSOR Connections, 6(2), 1-5. https://doi.org/10.11120/msor.2006.06020012

Devlin, K. (2012). Introduction to Mathematical Thinking. Retrieved on July 16,2018 http://www.mat.ufrgs.br/ portosil/curso-Devlin.pdf

Devlin, K. (2013). What is mathematics? Retrieved on July 10, 2018 from http://crcrth650.wikispaces.umb.edu/file/view/Devlin+-+Background_Reading.pdf

Duch, B. J. (2001). Writing problems for deeper understanding. In B. J. Duch, S. E. Groh, \& D. E. Allen (Eds.), The Power of Problem-Based Learning: A Practical "How To" for Teaching Undergraduate Courses in Any Discipline. Falmer Press.

Eberle, F. (2010). Why Stem Education is Important. Retrieved on June 2612,2018 from https://www.isa.org/standards-and-publications/isa-publications/intechmagazine/2010/september/why-stem-education-is-important/ 
English, L. D., \& Sriraman, B. (2010). Problem-solving for the 21st century. In: Sriraman, B. \& English, L. Theories of mathematical education: Seeking new frontiers. (pp. 261-297). Heidelberg; Dordrecht; London; New York: Springer. https://doi.org/10.1007/978-3-642-00742-2_27

English, L. D., \& Kirshner, D. (2015). Changing agendas in international research in mathematics education. In L. D. English, \& D. Kirshner (Eds.), Handbook of international research in mathematics education (pp. 3-18). New York, NY: Taylor and Francis. https://doi.org/10.4324/9780203448946

Hughes, R., Monaghan, J., Shingadia, E., \& Vaughan, S. (2006). Revisiting routine questions. Teaching Mathematics and its Applications: International Journal of the IMA, 25(2), 90-96. https://doi.org/10.1093/teamat/hri011

Intan Zulaika, A. (2016). Declining number of Malaysian students taking science and math in school: Here's why. Retrieved on July 12, 2018 from http://www.malaysiandigest.com/news/614553-decliningnumberof-malaysian-students-taking-scienceand-math-in-school-heres-why.html.

Irish Academy of Engineering. (2004). The Role of Mathematics in Engineering Education. Irish Academy of Engineering, Dublin.

James, W., \& High, K. (2008). Freshman-Level Mathematics in Engineering: A Review of the Literature in Engineering Education. American Society for Engineering Education (ASEE) Annual Conference \& Exposition. City: Pittsburgh, PA. https://doi.org/10.1007/s10665-007-9165-3

Katehi, L. (2005). The Global Engineer. In N. A. o. Engineering, (ed.), Educating the Engineer of 2020. Washington, DC: The National Academies Press, pp. 151- 155.

Kilpatrick, J., Swafford, J., \& Findell, B. (Eds.). (2001). Adding it up: Helping children learn mathematics. Washington, DC: National Academy Press.

King, R. (2008). Addressing the Supply and Quality of Engineering Graduates for the New Century. University of Sydney, Sydney.

Liu, P. H., \& Niess, M. L. (2006). An exploratory study of college students' views of mathematical thinking in a historical approach calculus course, math. Think \& Learn, 8(4), 373406. https://doi.org/10.1207/s15327833mtl0804_2

Lucas, M. S., \& McCormick, N. J. (2007). Redesigning mathematics curriculum for underprepared college students. The Journal of Effective Teaching, 7(2), 36-50.

Maheshwari, V. K. (2016). The Heuristic Strategy. Retrieved on July 13, 2018 from http://www.vkmaheshwari.com/WP/?p=2370

Malaysian Education Blue Print. (2013-2025). Retrieved on July 6, 2018 from https://www.moe.gov.my/images/dasar-kpm/articlefile_file_003108.pdf

Meng, C. C., Idris, N., \& Eu, L. K. (2014). Secondary Students' Perceptions of Assessments in Science, Technology, Engineering, and Mathematics (STEM). EURASIA Journal of Mathematics, Science \& Technology Education, 10(3), 219-227. https://doi.org/10.12973/eurasia.2014.1070a

Nasa, A., \& Anwar, Z. (2016). Too few STEM students. Retrieved on July 8, 2018 from https:/www.nst.com.my/news/2016/05/147260/too-few-stem-students

Parmjit, S. (2009). Variation in first year college students' understanding on their conceptions of and approaches to solving mathematical problems. Asian Journal for University Learning and Teaching, 5(1), 95-118.

Parmjit, S., \& Allan, W. (2006). Unpacking first year university students' mathematical content knowledge through problem solving. Asian Journal of University Education, 1(1), 33-56. Hanford (2012)

Parmjit, S., Teoh, S. H., Rasid, N. S., Md Nasir, N. A., Cheong, T. H., Abdul Rahman, N. (2016). Teaching and learning of college mathematics and student mathematical thinking: are the lines of the same track? Asian Journal of University Education, 12(2), 69-84.

Pearson, R. W. (1991). Why Don't Most Engineers Use Undergraduate Mathematics in Their Professional Work? Undergraduate Mathematics Education Trends, 3(4), 8.

Polya, G. (1973). How to solve it: A new aspect of mathematical model. (2nd ed). Princeton, New Jersey: Princeton University Press.

Prieto, E., Holbrook, A., Bourke, S., O’Connor, J., Page, A., \& Kira, H. (2009). Influences on Engineering Enrolments. A Synthesis of the Findings of Recent Reports. European Journal of Engineering Education, 34(2), 183-203. https://doi.org/10.1080/03043790902835940 
Radzi, N. M., Abu, M. S., \& Mohamad, S. (2009). Math-oriented critical thinking skills in engineering. IEEE 2009 (Dec, 7 - 8) International Conference on Engineering Education (ICEED), 212-218. Retrieved on July 19, 2018 from https://vdocuments.site/documents/ieee-2009-international-conference-onengineering-education-iceed-kuala-58c2990a9663a.html

Randall, C., \& Lester, F. K. (1 984). An Evaluation of a process-oriented instructional program in mathematical problem solving in grades 5 and 7. Journal for Research in Mathematics Education, 15(1), 1 5-34.

Reys, R. E., Lindquist, M.M., Lambdin, D. V., Suydam, M. N., \& Smith, N. L. (2001). Helping children learn mathematics (6th ed.), New York: Wiley.

Saritas, T., \& Akdemir, O. (2009). Identifying Factors Affecting the Mathematics Achievement of Students for Better Instructional Design. Retrieved on Sept 11, 2018 from http://www.itdl.org/journal/dec_09/article03.htm

Schoenfeld, A. H. (1980). Teaching problem-solving skills. Mathematical Association of America, 87(10), 794805.

Schoenfeld, A. H. (1985). Mathematical problem solving. San Diego, California. Academic Press Inc.

Schoenfeld, A. H. (1988). When Good Teaching Leads to Bad Results: The Disasters of Well Taught Mathematics $\quad$ Classes. $\quad$ Educational $\quad$ Psychologist, $\quad 23(2), \quad$ 145-166. https://doi.org/10.1207/s15326985ep2302_5

Schoenfeld, A. H. (1992). Learning to think mathematically: Problem solving, metacognition, and sensemaking in mathematics. In D. Grouws (Ed.), Handbook for Research on Mathematics Teaching and Learning (pp. 334-370). New York: MacMillan.

Schroeder, T. L., \& Lester, F. K. (Jr.). (1989). Developing understanding in mathematics via problem-solving. In: P.R. Trafton (ed.), New directions for 182 elementary school mathematics, 1989 Yearbook of the National Council of Teachers of Mathematics (NTCM). (pp. 31-42). Reston, VA: NTCM.

Tiong, Y. S. J., Hedberg J., \& Lioe L. T. (2005). A Metacognitive Approach to Support Heuristic Solution of Mathematical Problems. Paper represented at International Conference on Education, Redesigning pedagogy: research, policy, practice, 30 May - 1 June 2005. Singapore: National Institute of Education.

Treffinger, D., Selby, E., \& Isaksen, S. (2008). Understanding individual problem-solving style: A key to learning and applying creative problem solving. Learning and Individual Differences, 18, 390401. https://doi.org/10.1016/j.lindif.2007.11.007

Underwood, D. (1997). Is Mathematics Necessary? The College Mathematics Journal, 28(5), 360-364. https://doi.org/10.1080/07468342.1997.11973890

Zachry, E. M. (2008). Promising instructional reforms in developmental education: A case study of three achieving the Dream colleges. New York: MDRC. Retrieved on July 8, 2018 from https:/www.carnegiefoundation.org/wp-content/uploads/2013/05/stigler_dev-math.pdf

Zeidenberg, M., Jenkins, D., \& Calcagno, J. C. (2007). Do student success courses actually help community college students succeed? New York: Columbia University, Teachers College, Community College Research Center. Retrieved on Sept 11, 2018 from https:/www.carnegiefoundation.org/wpcontent/uploads/2013/05/stigler_dev-math.pdf 